\title{
Por um consenso conceitual e metodológico nas pesquisas em depressão pós-parto
}

\author{
For a conceptual and methodological consensus on postpartum depression \\ research \\ Amaury Cantilino
}

Prezado editor,

Agradecemos o interesse e as considerações feitas por Figueira et al. a respeito do nosso estudo.

Num país de dimensões continentais como o Brasil, certamente são encontrados fatores relacionados à cultura e a condições socioeconômicas que podem impactar nos resultados de pesquisas epidemiológicas. Contudo, da mesma maneira que Figueira et al., ponderamos em nossa discussão que os instrumentos utilizados na coleta de dados, assim como o período de pós-parto avaliado e sítios de abordagem das puérperas, também podem ser responsáveis por diferenças nas taxas do diagnóstico averiguado'.

Parece relevante que uma das condições clínicas mais estudadas da psiquiatria, como é a depressão pós-parto, ainda padeça de considerável carência de consenso em importantes questões que guiariam a metodologia das diversas pesquisas. Qual o período do pós-parto ideal para que se realize triagem? Deve-se diagnosticar como depressão pós-parto apenas aqueles quadros incidentes no puerpério? Até que mês após o parto se pode considerar que uma condição clínica tem relação com ele?

O problema instalado é que cada pesquisador acaba utilizando sua própria perspectiva para projetar seu estudo. Isso gera grande dificuldade de comparação entre os resultados. Até onde conhecemos, para a averiguação da prevalência de depressão pós-parto no Brasil, há os sete estudos citados no artigo em tela' somados à pesquisa de Figueira et al. ${ }^{2}$. Se quiséssemos realizar uma metanálise, não conseguiríamos obter sequer dois deles com metodologia igual. Assim, além de podermos promover dados atualizados no futuro, apontamos para a necessidade de criarmos "consensos metodológicos" no sentido de termos dados comparáveis entre centros e percebermos melhor quais variáveis realmente fazem a diferença.

\section{REFERÊNCIAS}

1. Cantilino A, Zambaldi CF, Albuquerque TLC, Paes JA, Montenegro ACP, Sougey EB. Postpartum depression in Recife - Brazil: prevalence and association with bio-socio-demographic factors. J Bras Psiquiatr. 2010;59(1):1-9.

2. Figueira P, Correa H, Malloy-Diniz L, Romano-Silva MA. Edinburgh Postnatal Depression Scale for screening in the public health system. Rev Saude Publica. 2009;43(Suppl 1):79-84.

1 Universidade Federal de Pernambuco (UFPE), Programa de Saúde Mental da Mulher. 